\title{
Effects of changes in Solid Oxide Fuel Cell Electrode Thickness on Ohmic and Concentration Polarizations
}

Shichuan Su ${ }^{a}$, Qiang Zhang ${ }^{a}$, Xiang Gao ${ }^{a}$, Vijay Periasamy ${ }^{b}$, and Wei Kong ${ }^{a, *}$

${ }^{a}$ School of Energy and Power Engineering, Jiangsu University of Science and Technology, 212003, Zhenjiang, Jiangsu, China

${ }^{b}$ Department of Chemical Engineering, Curtin University, WA 6845, Australia

Corresponding author, E-mail addresses: wkong@just.edu.cn

Abstract: In order to address the shortcomings of the solid oxide fuel cell (SOFC) associated with the thin electrode, the anode-cathode-supported SOFC (ACSC) is proposed in this study. In the ACSC, the electrolyte is thin, while both the anode and cathode have enough thickness to act as self-supporting layers. The mathematical models of both the anode-supported SOFC (ASC) and ACSC are established, which capture the intricate interdependency among the charge and gas transport, and the electrochemical reactions. The validity of the mathematical model is preliminarily verified by the good agreement between the numerical and experimental $I-V$ curves of the ASC button cell. For the same base case parameters and operating conditions, the average current density of ASC is 6388 $\mathrm{A} \mathrm{m}^{-2}$, only $83 \%$ of the ACSC, $7713 \mathrm{~A} \mathrm{~m}^{-2}$. The advantages of ACSC mainly stem from two aspects: i) the increased oxygen concentration under the solid rib covered zone, which extends the reaction active zone; ii) the increased cross section of the electric current transport path, which greatly decreases the cathode ohmic polarization. The performance comparison between the ACSC and ASC are examined by systematically varying the cathode electric conductivity, porosity, tortuosity factor and the output voltage. The results indicated that the advantage of ACSC over ASC is always obvious although the performance of ACSC varies with different parameters. 
Key words: Solid oxide fuel cell; Support design; Cathode thickness; Electric current collection; Oxygen transport; Numerical simulation 


\section{Introduction}

The fuel cell, which is an eco-friendly and highly efficient power generation device, has become the research hotspot recently [1-5]. Compared with the other type of fuel cells, the solid oxide fuel cell (SOFC) has many significant advantages such as the all solid-state structure, fuel flexibility and the non-dependence on expensive catalysts. Thus, in recent years, SOFC have received much more attention [6-9].

Traditionally, a typical planar solid oxide fuel cell (SOFC) consists of the electrolyte, anode and cathode layers; and the thickest layer is the support layer to satisfy the mechanical requirement. Up to now, the SOFC can be divided into four types based on the different support designs: a) the electrolyte-supported SOFC (indicated as ESC); b) the cathode-supported SOFC (CSC); c) the anode-supported SOFC (ASC); and d) the metalsupported SOFC (MSC) [10-13]. In the past decades, ESC with a typical electrolyte thickness around 150-300 $\mu \mathrm{m}$ was widely adopted. To reduce the large ohmic potential loss caused by the thick electrolyte, the ESCs were usually operated at a high temperature region $800 \sim 1000{ }^{\circ} \mathrm{C}$ [14]. However, high operation temperature requires strict material compatibility constraints, high manufacturing costs, shorting of the lifetime and challenging operational complexity. After that, the CSC, ASC and MSC with the thin electrolytes (i.e., 10-30 $\mu \mathrm{m}$ ) were designed to work around the intermediate and low temperature zone, which significantly reduce the ohmic polarizations $[15,16]$.

As the open circuit voltage of a single cell is only around $1 \mathrm{~V}$, many single cells are assembled into a stack through interconnectors in the form of series, parallel or seriesparallel connection to meet the high potential output demands [17-20]. Many grooves are milled on the interconnector to act as the gas channels to supply the reactant gases and 
exhaust the products. The remaining part of the interconnectors are the ribs which maintain contact with the electrodes to collect the produced current [21]. The electric current and gases transport paths in the typical support designs are illustrated in Fig. 1a and $\mathbf{b}$, respectively. Firstly, the typical widths of the channel and rib are about several millimeters $[22,23]$. Thus, the transport paths of the electric current (or gas) in the $x$ direction (parallel to the electrode surface) is greatly longer than its transport path in the $y$ direction (normal to the electrode surface). Secondly, in the conventional CSC, ASC or MSC structure, the electrode other than the support layer is very thin, only about $50 \mu \mathrm{m}$. It means that the cross-sectional areas of the $x$ direction transport paths for both the electric charges and gases in this thinner electrode are extremely small. These two factors can tremendously increase the transport resistance of the gases (or electric current) in $x$ direction; and cause large concentration loss (or ohmic loss). Taking the ASC with a thick support anode layer as an example, the thin cathode will seriously hinder the oxygen diffusion to those three phase boundaries (TPBs) under the solid rib. A $0.46 \mathrm{~mm}$ wide oxygen depletion region in the cathode of ASC was reported by Liu et al., which consists of almost $23 \%$ of the TPBs [24]. Our previous study also revealed that in the anode of CSC, the hydrogen concentration under the rib is only around one third of that under the channel covered zone [25]. Jeon et al. reported a comprehensive microscale model and investigated the electronic potential loss in the cathode. In their study, the cathode consists of a $20 \mu \mathrm{m}$ function layer and a 50 $\mu \mathrm{m}$ current collection layer, and the rib width is $2 \mathrm{~mm}$. With this configuration, they found that electronic potential in the cathode primarily varies in rib width direction due to large in-plane ohmic loss caused by thin cathode, which is about $60 \mathrm{mV}$; another interesting found is that the electronic current mainly flows in cathode current layer [26]. Geisler et al. 
examined the effect of rib on the ASC performance. An oxidant starvation zone was found under the rib cover zone due to the very thin cathode, which implied a dramatic slowdown in the performance. Similarly, the produced electric current density under the rib dropped from $1.6 \mathrm{~A} \mathrm{~cm}^{-2}$ to almost zero [18].

To overcome the shortcomings that are caused by the very thin electrode in the ASC, CSC and MSC, the anode-cathode-supported SOFC (ACSC) is proposed in this study, as illustrated in Fig. 1c and d. In the ACSC, the electrolyte is thin, while both the anode and cathode have enough thickness to act as self-supporting layers. Here, it is interesting to compare the ACSC with the NASA's bi-electrode supported SOFC (BSC) [27-29]. In order to meet the high specific power density and low weight in aerial application, the BSC incorporated gas channels into the electrodes rather than the interconnector, so the interconnector is only a thin ceramic film. In this manner, the interconnector will no longer be responsible for the distribution of gases, and only be here to separate the fuel and air. However, the ACSC configuration proposed here is totally different from NASA's architecture, simply because the ACSC keeps the original appearances and functions of interconnector and electrodes. By manipulating the electrode thickness, it overcomes the shortcomings associated with thin electrode. In this way, we create a relatively easy to implement and novel approach to this issue.

Considering that the ASC has been more widely studied than the CSC and MSC, the performances between ASC and ACSC under different conditions are calculated and compared to illustrate the advantages of the ACSC.

\section{Theoretical method}

\subsection{Physical model}


Fig. 2 depicts the cross section of a repeat cell unit in a typical planar SOFC stack, which is an anode-electrolyte-cathode single cell sandwiched between two interconnectors. Generally, the electrodes are layered, e.g., the cathode consists of cathode function layer (CFL) and cathode current collection layer (CCCL), the former provides more reaction place and the latter is responsible for the gas and charge transfer. However, based on two facts, CFL can be degraded into a boundary condition at the interface of cathode and electrolyte. First, CFL is generally thinner than CCCL and the actual electrochemical reaction depth is even shallower [18], second the CCCL thickness is the main factor that influence the gas and charge transfer, as paper [30] revealed, more electronic current flows through CCCL. So, the cathodes appear in Fig. 1 and Fig. 2 are actually the CCCL, which is the main concern while addressing the "high ohmic losses and oxygen starvation" in cathode. So here the function layers in cathode and anode will be treated as boundary conditions at the cathode-electrolyte and anode-electrolyte interfaces. Considering the symmetry, only half of a repeat unit is chosen as the computational domain (indicated with the blue line frame). The width of this computational domain is noted as $d_{\text {pitch }}$; it's the sum of one half of the rib width $d_{\text {rib }}$ and one half of the channel width $d_{\text {channel. The height of the }}$ computational domain is the total thickness of the cathode, electrolyte and anode.

\subsection{Charge transport}

Excluding distributed charge transfer, electronic and ionic electric current densities are governed by the charge continuity equations and Ohm's law, which can be described as follows:

$$
\begin{gathered}
\nabla i_{\mathrm{el}}=\nabla\left(-\sigma_{\mathrm{el}}^{\mathrm{eff}} \nabla \varphi_{\mathrm{el}}\right)=0, \\
\nabla i_{\mathrm{io}}=\nabla\left(-\sigma_{\mathrm{io}}^{\mathrm{eff}} \nabla \varphi_{\mathrm{io}}\right)=0,
\end{gathered}
$$


where $i_{\mathrm{el}}$ and $i_{\mathrm{io}}$ are the electronic and ionic electric current densities, respectively, $\varphi_{\mathrm{el}}$ and $\varphi_{\text {io }}$ denote the local electronic and ionic potentials.

$\sigma_{\mathrm{el}}^{\text {eff }}$ and $\sigma_{\mathrm{io}}^{\text {eff }}$ are the effective electronic and ionic conductivities, respectively. They can be evaluated as the function of the electrode microstructure as:

$$
\begin{aligned}
& \sigma_{\mathrm{el}}^{\mathrm{eff}}=\sigma_{\mathrm{el}}^{0}\left[(1-\varepsilon) \phi_{\mathrm{el}} p_{\mathrm{el}}\right]^{B}, \\
& \sigma_{\mathrm{io}}^{\mathrm{eff}}=\sigma_{\mathrm{io}}^{0}\left[(1-\varepsilon) \phi_{\mathrm{io}} p_{\mathrm{io}}\right]^{B},
\end{aligned}
$$

where $\sigma_{\mathrm{el}}^{0}$ and $\sigma_{\mathrm{io}}^{0}$ are the intrinsic electronic and ionic conductivities of the dense materials, respectively. $\varepsilon$ is the porosity, and $\phi_{\mathrm{el}}$ and $\phi_{\mathrm{io}}$ are the volume fractions of the electronic and ionic conductors, respectively. $p_{\mathrm{el}}\left(\right.$ or $\left.p_{\mathrm{io}}\right)$ is the probability of the electronic (or ionic) conductor particles to belong to the percolated clusters. $B$ is the Bruggeman factor used to include the effect of tortuous conduction paths, which is set as 3.5 [31]. What noteworthy is that Bruggeman effective medium theory is valid when the media was composed of isotropic particles, usually spheres and cylinders, so, it cannot capture the anisotropy in some complex non-ideal structures [32]. But usually SOFC electrode is represented by random sphere packing system, so Bruggeman effective medium theory can be applied to it with careful verification, like in paper [31].

The intrinsic electric conductivities of dense Ni, LSM and YSZ materials are greatly dependent on $T[30]$ :

$$
\begin{aligned}
& \sigma_{\mathrm{Ni}}^{0}=3.27 \times 10^{6}-1065.3 T, \\
& \sigma_{\mathrm{LSM}}^{0}=\frac{4.2 \times 10^{7}}{T} \exp \left(-\frac{Q_{\mathrm{LSM}}}{T}\right), \\
& \sigma_{\mathrm{YSZ}}^{0}=3.34 \times 10^{4} \exp \left(-\frac{Q_{\mathrm{YSZ}}}{T}\right),
\end{aligned}
$$


in which $Q_{\mathrm{LSM}}=1150 \mathrm{eV}$ and $Q_{\mathrm{YSZ}}=10300 \mathrm{eV}$.

\subsection{Mass transport}

The dusty gas model is adopted to model the mass transport in the porous electrode structure $[33,34]$;

$$
\frac{N_{i}}{D_{i \mathrm{~K}}^{\mathrm{eff}}}+\sum_{j=1}^{n} \frac{x_{j} N_{i}-x_{i} N_{j}}{D_{i j}^{\mathrm{eff}}}=-\frac{1}{R T}\left(p \nabla x_{i}+x_{i} \nabla p+x_{i} \nabla p \frac{k p}{D_{i \mathrm{~K}}^{\mathrm{eff}} \mu}\right),
$$

where $N_{i}$ and $x_{i}=c_{i} / c_{\text {tot }}$ are the molar flux and molar fraction of species $i$, respectively; $c_{i}$ is the molar concentration of species $i, c_{\text {tot }}=\operatorname{sum}\left(c_{1}: c_{n}\right), R$ is the universal gas constant, $p$ is the total gas pressure, $k$ is the permeability coefficient and $\mu$ is the viscosity coefficient.

$D_{i \mathrm{~K}}^{\mathrm{eff}}$ is the effective Knudsen diffusion coefficients of species $i$; and $D_{i j}^{\mathrm{eff}}$ is the effective binary diffusion coefficient. They can be evaluated by the equations [35-37]:

$$
\begin{aligned}
& D_{i j}^{\mathrm{eff}}=\frac{\varepsilon}{\tau} \frac{3.198 \times 10^{-8} T^{1.75}}{p\left(v_{i}^{1 / 3}+v_{j}^{1 / 3}\right)^{2}}\left(\frac{1}{M_{i}}+\frac{1}{M_{j}}\right)^{0.5}, \\
& D_{i \mathrm{~K}}^{\mathrm{eff}}=\frac{\varepsilon}{\tau} \frac{2}{3} r_{\mathrm{g}} \sqrt{\frac{8 R T}{\pi M_{i}}}, \\
& r_{\mathrm{g}}=\frac{2}{3} \frac{\varepsilon}{1-\varepsilon} \frac{1}{\phi_{\mathrm{el}} / r_{\mathrm{el}}+\phi_{\mathrm{io}} / r_{\mathrm{io}}},
\end{aligned}
$$

where $\tau$ is the tortuosity factor, $v_{i}$ and $M_{i}$ are the diffusion volume and molecular mass of species $i$, respectively, $r_{\mathrm{g}}$ is the pore radii, $r_{\mathrm{el}}\left(\right.$ or $\left.r_{\mathrm{io}}\right)$ is the average radius of the electronic (or ionic) conductor.

\subsection{Boundary conditions}

As described above, the mass transport and charge transport equations are taken into account in this model. Appropriate boundary conditions are required to solve these coupled 
partial differential equations. Table 1 gives the boundary conditions for both the electron and ion conduction equations. Due to the oxidation of the steel rib, the effect of the contact resistance at the rib-electrode interface is considered. The electric current densities that pass through both the rib-anode interface $i_{\text {rib } \rightarrow \text { An }}$ and the rib-cathode interface $i_{\text {Ca } \rightarrow \text { rib }}$ can be related to the contact resistances as:

$$
\begin{gathered}
i_{\text {rib } \rightarrow \mathrm{An}}=\frac{\varphi_{\text {e,rib/An }}-\varphi_{\mathrm{e}, \mathrm{A} n / \mathrm{rib}}}{A S R_{\mathrm{contact}}}, \\
i_{\mathrm{Ca} \rightarrow \mathrm{rib}}=\frac{\varphi_{\mathrm{e}, \mathrm{Ca} / \mathrm{rib}}-\varphi_{\mathrm{e}, \mathrm{rib} / \mathrm{Ca}}}{A S R_{\text {contact }}},
\end{gathered}
$$

where $A S R_{\text {contact }}$ is the contact resistance at the rib-electrode interface. For the rib-anode interface, $\varphi_{\mathrm{e}, \mathrm{rib} / \mathrm{An}}$ and $\varphi_{\mathrm{e}, \mathrm{An} / \mathrm{rib}}$ are the electric potentials at the rib and anode side, respectively; and the definitions are analogous for $\varphi_{\mathrm{e}, \mathrm{Carib}}$ and $\varphi_{\mathrm{e}, \mathrm{rib} / \mathrm{Ca}}$ at the rib-cathode interface.

In Table 1, $i_{\text {trans }}^{\text {an }}$ and $i_{\text {trans }}^{\text {ca }}$ are the transfer electronic and ionic electric current densities in anode and cathode sides, respectively, which can be calculated by Butler-Volmer equations indicated below. In order to derive the apparent dependences on partial pressure, some assumptions are made [38]: for hydrogen oxidation, five reaction steps are counted in the anode TPB, which involve six surface species and two gas-phase species, and the rate-limiting reaction is: $\mathrm{H}(\mathrm{Ni})+\mathrm{OH}^{-}(\mathrm{YSZ}) f(\mathrm{Ni})+\mathrm{H}_{2} \mathrm{O}(\mathrm{YSZ})+\mathrm{e}^{-}(\mathrm{Ni})$. For oxygen reduction, two reaction steps are considered: an adsorption-desorption step and a chargetransfer step, and the latter is assumed to be rate-limiting.

$$
i_{\text {trans }}^{\text {an }}=i_{\text {ref }}^{\text {an }} \exp \left(-\frac{E_{\mathrm{H}_{2}}}{R}\left(\frac{1}{T}-\frac{1}{T_{\text {ref }}}\right)\right)\left(\frac{p_{\mathrm{H}_{2}}^{\mathrm{TP}} p_{\mathrm{H}_{2} \mathrm{O}}^{\mathrm{TPB}}}{p_{\mathrm{H}_{2}}^{0} p_{\mathrm{H}_{2} \mathrm{O}}^{0}}\right)\left[\exp \left(\frac{2 \alpha_{\mathrm{f}}^{\mathrm{an}} F}{R T} \eta_{\mathrm{act}}^{\text {an }}\right)-\exp \left(-\frac{2 \beta_{\mathrm{r}}^{\mathrm{an}} F}{R T} \eta_{\mathrm{act}}^{\mathrm{an}}\right)\right],
$$




$$
i_{\text {trans }}^{\mathrm{ca}}=i_{\text {ref }}^{\mathrm{ca}} \exp \left(-\frac{E_{\mathrm{O}_{2}}}{R}\left(\frac{1}{T}-\frac{1}{T_{\text {ref }}}\right)\right)\left(\frac{p_{\mathrm{O}_{2}}^{\mathrm{TPB}}}{p_{\mathrm{O}_{2}}^{0}}\right)^{0.25}\left[\exp \left(\frac{2 \alpha_{\mathrm{f}}^{\mathrm{ca}} F}{R T} \eta_{\mathrm{act}}^{\mathrm{ca}}\right)-\exp \left(-\frac{2 \beta_{\mathrm{r}}^{\mathrm{ca}} F}{R T} \eta_{\mathrm{act}}^{\mathrm{ca}}\right)\right],
$$

herein, $\eta_{\text {act }}^{\text {an }}$ and $\eta_{\text {act }}^{\text {ca }}$ are the anode and cathode activation over-potentials, respectively:

$$
\begin{aligned}
& \eta_{\mathrm{act}}^{\mathrm{an}}=\varphi_{\mathrm{el}}-\varphi_{\mathrm{io}}-\eta_{\mathrm{conc}}^{\mathrm{an}}=\varphi_{\mathrm{el}}-\varphi_{\mathrm{io}}-\frac{R T}{2 F} \ln \left(\frac{p_{\mathrm{H}_{2}}^{0}}{p_{\mathrm{H}_{2} \mathrm{O}}^{0}} \frac{p_{\mathrm{H}_{2} \mathrm{O}}^{\mathrm{TPB}}}{p_{\mathrm{H}_{2}}^{\mathrm{TPB}}}\right), \\
& \eta_{\mathrm{act}}^{\mathrm{ca}}=\varphi_{\mathrm{io}}-\varphi_{\mathrm{el}}-\eta_{\mathrm{conc}}^{\mathrm{ca}}=\varphi_{\mathrm{io}}-\varphi_{\mathrm{el}}-\frac{R T}{4 F} \ln \left(\frac{p_{\mathrm{O}_{2}}^{0}}{p_{\mathrm{O}_{2}}^{\mathrm{TPB}}}\right),
\end{aligned}
$$

where $\alpha_{\mathrm{f}}$ and $\beta_{\mathrm{r}}$ are the forward and reverse reaction symmetry factors, respectively; $E_{\mathrm{H}_{2}}$ and $E_{\mathrm{O}_{2}}$ are the activation energies for the anode and cathode electrochemical reactions, respectively. $T_{\text {ref }}$ is the reference temperature, $i_{\text {ref }}^{\text {an }}$ and $i_{\text {ref }}^{\text {ca }}$ are often deduced from experiments or assigned empirically at the reference temperature $T_{\text {ref }}$ and $F$ is the Faraday constant. $\eta_{\text {conc }}^{\text {an }}$ and $\eta_{\text {conc }}^{\text {ca }}$ are the anode and cathode concentration over-potentials. $p_{i}^{0}$ is the partial pressure of reactant species $i$ at the fuel (or air) channel-electrode interface. $p_{i}^{\mathrm{TPB}}$ is the local partial pressure of $i$ at the TPB reaction sites.

Table 2 lists the boundary settings for the mass transport equations. Since the electrochemical reactions are assumed to happen around the electrode-electrolyte interface, the species molar sources are set on the corresponding boundaries.

\subsection{Model parameters and model validation}

The model is implemented in the commercial finite element software COMSOL MULTIPHYSICS $^{\circledR}$. The Direct solver MUMPS is used to solve the coupled charge transport and gas transport equations with a relative convergence tolerance of $1 \times 10^{-6}$. A rectangular structured grid is used to discretize the geometric construction. 
To verify the validity of the model, a button cell with the same parameters and settings from [39] is built and tested. All relevant parameters, including those from the reference and those fitted, are listed in Table. 3. Fig. 3 shows the comparison of the numerical results with the experimental $I-V$ relationship. The numerical model result matches very well with the experiment result, thus justifies the parameters and settings of the button cell model. After validating this group of parameters and settings, a planer SOFC model channel width $w_{\mathrm{ch}}=1.0 \mathrm{~mm}$ and rib width $w_{\text {rib }}=1.0 \mathrm{~mm}$ is built based on the same conditions (unless specified differently) for a following study.

For the following study on planar SOFC, two kinds of meshes with different sizes are built to ensure the mesh independence of the calculated result. Mesh A has 1120 cells, while the mesh B has 2400 cells. The calculated result shows that the deviation between the result from mesh A and the result from mesh B is less than $0.01 \%$; and the mesh A is adopted in the following research.

\section{Results and discussion}

\subsection{Comparison of physical quantity distribution}

In order to investigate the performance discrepancy between the ASC and ACSC, two models are developed with the same parameters and settings as described in Table 3, except for the thicknesses of the electrode layers. The anode and cathode thicknesses of the ASC model are 0.5 and $0.05 \mathrm{~mm}$, respectively, while the corresponding values for the ACSC model are 0.35 and $0.35 \mathrm{~mm}$, respectively. With the model parameters in Table 3 (basis case), the calculated average current density of ASC is $i_{\text {ave }}=6388 \mathrm{~A} \mathrm{~m}^{-2}$, which is $17 \%$ less than the current density of the ACSC, $i_{\mathrm{ave}}=7713 \mathrm{~A} \mathrm{~m}^{-2}$. The performance discrepancy between the ASC and the ACSC may be attributed to the different ohmic and concentration 
polarizations in electrodes: the average ohmic polarization in cathode of ACSC stack is 4.8 $\mathrm{mV}$, which is only about one fifth of that in ASC $(27 \mathrm{mV})$. Similarly, the average concentration polarization in cathode of ACSC is $35 \mathrm{mV}$, while that of ASC is $99 \mathrm{mV}$. On the contrary, the average ohmic and concentration polarizations in anode of ACSC are 0.32 $\mathrm{mV}$ and $19 \mathrm{mV}$, respectively, which close to that in ASC $0.25 \mathrm{mV}$ and $15 \mathrm{mV}$. As a result, the total ohmic and concentration polarizations in the ACSC are quite smaller than that in the ASC, which is the main reason for the ACSC better performance.

To further analyze the reason for this discrepancy, the distributions of oxygen concentrations, current densities and potentials in both the ACSC and ASC are examined in the following. Fig. 4a illustrates the distribution of oxygen concentration within the ASC cathode. Although the $c_{\mathrm{O}_{2}}$ in $y$ direction is distributed uniformly, it varies considerably in $x$ direction. Especially in the zone covered by the cathode rib, the $c_{\mathrm{O}_{2}}$ is quite small; and the minimum $c_{\mathrm{O}_{2}}$ is only $2.03 \times 10^{-6} \mathrm{~mol} \mathrm{~m}$. This is because that a very thin cathode will extremely limits the oxygen diffusion in the $x$ direction. Compared with ASC, the ACSC cathode has more wide variation of $c_{\mathrm{O}_{2}}$ in the $y$ direction (shown in Fig. $\mathbf{4 b}$ ), because the relative thicker cathode extends the oxygen transmission distance in $y$ direction. However, it is interesting to note that the relatively thicker cathode would also provide a wider alleyway to enhance the oxygen transport along the $x$ direction. Therefore, as shown in Fig. 4c, for the $x>1.2 \mathrm{~mm}$ zone, the $c_{\mathrm{O}_{2}}$ under the rib cover zone in an ACSC is significantly larger than that in an ASC.

Fig. 4c shows the comparison of the $c_{\mathrm{O}_{2}}$ distributions over the cathode-electrolyte interface in the ASC and the ACSC. Obviously, for a typical ASC, the oxygen 
concentration beyond the $x>1.4 \mathrm{~mm}$ zone is very close to zero. This phenomenon has also been encountered in paper $[18,30]$, which is to a great degree caused by the high current and thin cathode thickness. So, numerically, the electrochemical reaction can't occur in this zone due to the lack of the oxygen. Consequently, the produced current density is almost zero in this zone, as shown in Fig. 4d. For the ACSC, however, the $c_{\mathrm{O}_{2}}$ distributions within the rib covered zone (i.e., the $x>1.2 \mathrm{~mm}$ zone) are larger than that in an ASC. This means larger electric current density can be produced within cathode rib covered zone of the ACSC cathode than that in the ASC. It is worth to note that although the $c_{\mathrm{O}_{2}}$ over the cathode-electrolyte interface under the channel covered zone of ACSC $(x<1 \mathrm{~mm})$ is smaller than that of ASC, their produced electric current densities are similar. That is attributed to the lower ohmic loss in the ACSC than in the ASC, which is further supported by the calculated electric potential shown in Fig. 5. In conclusion, compared with the ASC, the ACSC design can greatly improve the oxygen concentration under the rib coved zone in the cathode side and extend the active reaction zone thereby significantly improving the cell performance. In other words, the extremely thin cathode thickness is an important factor that contributes to the performance reduction of the ASC stack.

Fig. 5 shows the cathode potential distributions both within the ASC and the ACSC. In the ASC cathode, although there is a small electric potential gradient in $y$ direction, a large gradient is seen in the $x$ direction. The electric potential, $\varphi_{\mathrm{el}}$, drops from 0.781 to $0.729 \mathrm{~V}$, which means the ohmic polarization within the cathode of the ASC is $52 \mathrm{mV}$. This notable cathode ohmic over-potential of the ASC stack is attributed to the following two factors: i) the narrow cross-section of electric current transport path in the $x$ direction; ii) the relatively small cathode electrical conductivity. Apparently, the cathode ohmic 
polarization within the ACSC cathode is only $8 \mathrm{mV}$, which is less than one sixth of that in the ASC. From these results, it is apparent that the ACSC cathode benefits from a larger cathode thickness, which provides a larger cross-sectional area for the electric current transport path in the $x$ direction, the lack of which is the main factor contributing to the poor performance of the ASC stack.

\subsection{The effect of parameters and operating conditions}

In this section, the effects of cell parameters and operating conditions on its performance are compared for the ASC and the ACSC designs. As shown in Fig. 6, the differences between the ACSC and ASC performances decrease with the increasing of the cathode conductivity. The performance of ASC is sensitive to cathode conductivity. While the cathode conductivity increases from 769.2 to $7692 \mathrm{~S} \mathrm{~m}^{-1}$, the average output current density increases by $38 \%$. This conclusion can be supported by Fig. 5. The performance of the ASC will be greatly increased by increasing the cathode conductivity, because of the very serious cathode ohmic polarization caused by the narrow cross section of the electric conducting path in the $x$ direction. On the contrary, as the ohmic loss in the ACSC cathode is already very small, limited effect on the performance can be obtained by increasing the electric conductivity. As shown in Fig. 6, the average current density of the ACSC only increased by $1.2 \%$, while the electric conductivity of the cathode increases from 3077 to $7692 \mathrm{~S} \mathrm{~m}^{-1}$.

Fig. 7 depicts the dependence of the average current density on the cathode porosity. Apparently, the performance of the ACSC is much better than that of the ASC for any practical cathode porosity. Furthermore, the gap between ACSC and ASC increases with increase in cathode porosity. It is interesting to note that although larger cathode porosity 
can cause smaller cathode concentration polarization, the performance of the ASC decrease with the increasing of the cathode porosity. That is attributed to the serious cathode ohmic polarization caused by the thin ACS cathode thickness. Although the bigger cathode porosity leads to a smaller concentration loss, it might also greatly reduce the cathode electric conductivity resulting in the increase of the $x$ direction conducting resistance that leads to a more serious ohmic polarization loss. Thus, the performance of the ASC decreases with the increase of the cathode porosity due to the increase of the total loss.

Fig. 8 shows the impact of the tortuosity factor on the average current density. With the increase of the cathode tortuosity factor, the average current density gradually reduces. The average current densities drop $18 \%$ and $8 \%$ for ACSC and ASC, respectively, while the cathode tortuosity factor increases from 2 to 5 . This is because the cathode concentration polarization in ACSC is greater than that in ASC due to a thicker cathode layer. However, it should be noted that even for the unusually large tortuosity factor case, the performance of the ACSC with a thicker cathode is better than that of the ASC.

Fig. 9 gives the output current density of ASC and ACSC in the range of the typical output potential zone. It is evident that two curves are nearly parallel to each other. This result indicates that the ACSC has a constant advantage over the ASC irrespective of the variations of both the output current and the output potential.

\section{Conclusions}

This study has proposed a novel bi-electrode supported solid oxide fuel cell (ACSC) design. To establish the advantages of the ACSC, both the ASC and the ACSC models are established. The oxygen concentration distribution and electric potential distribution within the ASC and ACSC cathodes are compared in detail. Furthermore, the performance 
differences between the ASC and ACSC are carefully investigated in the wide ranges of the cathode electric conductivity, porosity, tortuosity factor and the output electric potential. The conclusions are summarized as follows:

i) With the basis case parameters, the average current density of the ASC is $17 \%$ compared with that of the ACSC;

ii) The ACSC design improves the oxygen concentration distributions under the rib coved zone, extends the active reaction zone and reduces the cathode ohmic loss. The cathode electric potential difference is only $8 \mathrm{mV}$, which is less than one sixth of that in ASC;

iii) Although the difference in the performance between the ACSC and the ASC changes with the variation of the cathode electric conductivity, porosity, tortuosity factor, and output electric potential, the ACSC always out-performs the ASC.

\section{Acknowledgements}

We gratefully acknowledge the financial support of the National Science Foundation of China (21406095 and 21106058), the Jiangsu Province Colleges and Universities Natural Science Projects (13KJB480003) and the Jiangsu University of Science and Technology (35321101). 


\section{References}

[1] Kafafi ZH. Metal-free catalysts for fuel cell technology. Science. 2015;347:961-4.

[2] Plumeré N, Rüdiger O, Oughli AA, Williams R, Vivekananthan J, Pöller S, et al. A redox hydrogel protects hydrogenase from high-potential deactivation and oxygen damage. Nat Chem. 2014;6:822-7.

[3] Razbani O, Assadi M, Andersson M. Three dimensional CFD modeling and experimental validation of an electrolyte supported solid oxide fuel cell fed with methane-free biogas. Int $\mathbf{J}$ Hydrogen Energy. 2013;38:10068-80.

[4] Panthi D, Tsutsumi A. Micro-tubular solid oxide fuel cell based on a porous yttriastabilized zirconia support. Sci Rep. 2014;4. 5754: 1-6.

[5] Shen S, Ni M. 2D segment model for a solid oxide fuel cell with a mixed ionic and electronic conductor as electrolyte. Int J Hydrogen Energy. 2015;40:5160-8.

[6] Andersson M, Paradis H, Yuan J, Sundén B. Three dimensional modeling of an solid oxide fuel cell coupling charge transfer phenomena with transport processes and heat generation. Electrochim Acta. 2013;109:881-93.

[7] Kong W, Zhang Q, Gao X, Zhang J, Chen D, Su S. A Method for Predicting the Tortuosity of Pore Phase in Solid Oxide Fuel Cells Electrode. Int J Electrochem Sci. 2015;10:5800-11.

[8] Zheng K, Li L, Ni M. Investigation of the electrochemical active thickness of solid oxide fuel cell anode. Int J Hydrogen Energy. 2014;39:12904-12.

[9] Hu B, Wang Y, Xia C. Oxygen incorporation at the three-phase boundary of LSCF-SDC composite. J Power Sources. 2014;269:180-8.

[10] Kong W, Gao X, Liu S, Su S, Chen D. Optimization of the Interconnect Ribs for a Cathode-Supported Solid Oxide Fuel Cell. Energies. 2014;7:295-313.

[11] Zhou Y, Xin X, Li J, Ye X, Xia C, Wang S, et al. Performance and degradation of metalsupported solid oxide fuel cells with impregnated electrodes. Int $\mathbf{J}$ Hydrogen Energy. 2014;39:2279-85.

[12] Chen D, Wang H, Zhang S, Tade MO, Chen H, Shao Z. Multi - scale model for solid oxide fuel cell with electrode containing mixed conducting material. AIChE J. 2015;61:3786-3803.

[13] Kong Y, Hua B, Pu J, Chi B, Jian L. A cost-effective process for fabrication of metalsupported solid oxide fuel cells. Int J Hydrogen Energy. 2010;35:4592-6.

[14] Virkar AV, Chen J, Tanner CW, Kim J-W. The role of electrode microstructure on activation and concentration polarizations in solid oxide fuel cells. Solid State Ion. 2000;131:18998.

[15] Andersson M, Yuan J, Sundén B. SOFC modeling considering electrochemical reactions at the active three phase boundaries. Int J Heat Mass Transfer. 2012;55:773-88.

[16] Zhang Z, Yue D, Yang G, Chen J, Zheng Y, Miao H, et al. Three-dimensional CFD modeling of transport phenomena in multi-channel anode-supported planar SOFCs. International Int J Heat Mass Transfer. 2015;84:942-54.

[17] Yan M, Fu P, Chen Q, Wang Q, Zeng M, Pandit J. Electrical Performance and Carbon Deposition Differences between the Bi-Layer Interconnector and Conventional Straight Interconnector Solid Oxide Fuel Cell. Energies. 2014;7:4601-13.

[18] Geisler H, Kromp A, Weber A, Ivers-Tiffee E. Stationary FEM Model for Performance Evaluation of Planar Solid Oxide Fuel Cells Connected by Metal Interconnectors: I. Model Framework and Validation. J Electrochem Soc. 2014;161:F778-F88.

[19] Chen D, Zeng Q, Su S, Bi W, Ren Z. Geometric optimization of a 10-cell modular planar solid oxide fuel cell stack manifold. Appl Energy. 2013;121:1100-7.

[20] Wu W, Guan W, Wang W. Contribution of properties of composite cathode and cathode/electrolyte interface to cell performance in a planar solid oxide fuel cell stack. J Power Sources. 2015;279:540-8. 
[21] Su S, He H, Chen D, Zhu W, Wu Y, Kong W, et al. Flow distribution analyzing for the solid oxide fuel cell short stacks with rectangular and discrete cylindrical rib configurations. Int J Hydrogen Energy. 2015;40:577-92.

[22] Kornely M, Leonide A, Weber A, Ivers-Tiffée E. Performance limiting factors in anodesupported cells originating from metallic interconnector design. J Power Sources. 2011;196:720916.

[23] Kong W, Li J, Liu S, Lin Z. The influence of interconnect ribs on the performance of planar solid oxide fuel cell and formulae for optimal rib sizes. J Power Sources. 2012;204:106-15.

[24] Liu S, Song C, Lin Z. The effects of the interconnect rib contact resistance on the performance of planar solid oxide fuel cell stack and the rib design optimization. J Power Sources. 2008; 183:214-25.

[25] Kong W, Su SC, Gao X, Zhang DH, Yu ZD. Optimization of the Anode Current Collector Layer Thickness for the Cathode-Supported Solid Oxide Fuel Cell. Adv Mater Res. 2013;712715:1325-9.

[26] Jeon DH, Nam JH, Kim CJ. Microstructural optimization of anode-supported solid oxide fuel cells by a comprehensive microscale model. J Electrochem Soc. 2006;153:A406-A17.

[27] Cable TL, Sofie SW. A symmetrical, planar SOFC design for NASA's high specific power density requirements. J Power Sources. 2007;174:221-7.

[28] Cable TL, Setlock JA, Farmer SC, Eckel AJ. Regenerative performance of the NASA symmetrical solid oxide fuel cell design. Int J Appl Ceram Tec. 2011;8:1-12.

[29] Shi J, Xue X. Inverse estimation of electrode microstructure distributions in NASA Bielectrode supported solid oxide fuel cells. Chem Eng J. 2012;181-182:607-13.

[30] Jeon DH, Nam JH, Kim C-J. Microstructural Optimization of Anode-Supported Solid Oxide Fuel Cells by a Comprehensive Microscale Model. J Electrochem Soc. 2006;153:A406.

[31] Sanyal J, Goldin GM, Zhu H, Kee RJ. A particle-based model for predicting the effective conductivities of composite electrodes. J Power Sources. 2010;195:6671-9.

[32] Tjaden B, Cooper SJ, Brett DJL, Kramer D, Shearing PR. On the origin and application of the Bruggeman correlation for analysing transport phenomena in electrochemical systems. Current Opinion in Chemical Engineering. 2016;12:44-51.

[33] Shixue L, Wei K, Zijing L. Three-dimensional modeling of planar solid oxide fuel cells and the rib design optimization. J Power Sources. 2009:854-63.

[34] Kong W, Zhu H, Fei Z, Lin Z. A modified dusty gas model in the form of a Fick's model for the prediction of multicomponent mass transport in a solid oxide fuel cell anode. J Power Sources. 2012;206:171-8.

[35] Fuller EN, Schettler PD, Giddings JC. New method for prediction of binary gas-phase diffusion coefficients. Industrial \& Engineering Chemistry. 1966;58:18-27.

[36] Veldsink JW, Versteeg GF, Van Swaaij WPM, Van Damme RMJ. The use of the dustygas model for the description of mass transport with chemical reaction in porous media. The Chemical Engineering Journal and the Biochemical Engineering Journal. 1995;57:115-25.

[37] Todd B, Young JB. Thermodynamic and transport properties of gases for use in solid oxide fuel cell modelling. J Power Sources. 2002;110:186-200.

[38] Zhu H, Kee RJ, Janardhanan VM, Deutschmann O, Goodwin DG. Modeling Elementary Heterogeneous Chemistry and Electrochemistry in Solid-Oxide Fuel Cells. J Electrochem Soc. 2005;152:A2427-A40.

[39] Barzi YM, Raoufi A, Lari H. Performance analysis of a SOFC button cell using a CFD model. Int J Hydrogen Energy. 2010;35:9468-78. 


\section{List of Tables and Figures}

Table 1 Boundary condition settings for the electron and ion charge transfer equations

Table 2 Boundary condition (BC) settings for mass transports in electrodes

Table.3 Basic model parameters

Fig. 1 Schematic diagram of the charge and gas transport paths within the electrodes: a) gas transport paths in typical support designs; b) electric current conducting paths in typical support designs; c) gas transport paths in ACSC; d) electric current conducting paths in ACSC

Fig. 2 Schematic diagram of the cross section of a repeat cell unit in a typical SOFC stack

Fig. 3 Comparison of the theoretical and experimental $I-V$ relationship

Fig. 4 a) Distribution of the oxygen concentration in ASC cathode; b) Distribution of the oxygen concentration in ACSC cathode; c) Distribution of $c_{\mathrm{O}_{2}}$ over the cathode-electrolyte interface; d) Distribution of the produced electric current density at cathode-electrolyte interface

Fig. 5 Distribution of electric potential in cathode of the (a) ASC, (b) ACSC

Fig. 6 Dependence of the average current density on the effective electric conductivity of the cathode layer

Fig. 7 The effect of the cathode porosity on the average current density

Fig. 8 Dependence of the average current density on the cathode tortuosity factor

Fig. 9 The effect of the output voltage on the average current density 
Table. 1

\begin{tabular}{ccccccc}
\hline Equation & Boundary & $\begin{array}{c}\text { Rib-cathode } \\
\text { interface }\end{array}$ & $\begin{array}{c}\text { Rib-anode } \\
\text { interface }\end{array}$ & $\begin{array}{c}\text { Cathode- } \\
\text { electrolyte } \\
\text { interface }\end{array}$ & $\begin{array}{c}\text { Anode- } \\
\text { electrolyte } \\
\text { interface }\end{array}$ & Others \\
\hline $\begin{array}{c}\text { Electron } \\
\text { conduction } \\
\text { equation }\end{array}$ & $\begin{array}{c}\text { Boundary } \\
\text { type }\end{array}$ & $\begin{array}{c}\text { Reference } \\
\text { potential } \\
\left(\varphi_{\text {e,rib/Ca }}\right)\end{array}$ & $\begin{array}{c}\text { Reference } \\
\text { potential } \\
\left(\varphi_{\text {e,rib/An }}\right)\end{array}$ & $\begin{array}{c}\text { Normal inward } \\
\text { current density }\end{array}$ & $\begin{array}{c}\text { Normal inward } \\
\text { current density }\end{array}$ & $\begin{array}{c}\text { Electric } \\
\text { Insulation }\end{array}$ \\
\cline { 2 - 7 } & $\begin{array}{c}\text { Boundary } \\
\text { setting }\end{array}$ & $V_{\mathrm{op}}(0.7)$ & $E_{0}$ & $i_{\text {trans }}^{\text {ca }}$ & $-i_{\text {trans }}^{\text {an }}$ & Inner current \\
source & Inner current & source & Insulation \\
\hline $\begin{array}{c}\text { Ion } \\
\text { conduction } \\
\text { equation }\end{array}$ & $\begin{array}{c}\text { Boundary } \\
\text { type }\end{array}$ & $\begin{array}{c}\text { Boundary } \\
\text { setting }\end{array}$ & & $-i_{\text {trans }}^{\text {ca }}$ & $i_{\text {trans }}^{\text {an }}$ & \\
\hline Note: ("Electric Insulation" means that the normal component of the electric current is zero) & & \\
\hline
\end{tabular}

Note: ("Electric Insulation" means that the normal component of the electric current is zero). 
Table. 2

\begin{tabular}{|c|c|c|c|c|c|c|}
\hline Equation & Boundary & \multicolumn{2}{|c|}{ Anode-channel interface } & \multicolumn{2}{|c|}{ Anode-electrolyte interface } & Others \\
\hline \multirow{3}{*}{$\begin{array}{c}\text { Fuel } \\
\text { transport } \\
\text { equation }\end{array}$} & $\begin{array}{c}\text { Boundary } \\
\text { Type }\end{array}$ & $\begin{array}{c}\mathrm{H}_{2} \text { molar } \\
\text { concentration }\end{array}$ & $\begin{array}{l}\mathrm{H}_{2} \mathrm{O} \text { molar } \\
\text { concentration }\end{array}$ & $\begin{array}{c}\mathrm{H}_{2} \text { normal } \\
\text { inward molar } \\
\text { flow }\end{array}$ & $\begin{array}{c}\mathrm{H}_{2} \mathrm{O} \text { normal } \\
\text { inward molar } \\
\text { flow }\end{array}$ & Insulation \\
\hline & $\begin{array}{l}\text { Boundary } \\
\text { setting }\end{array}$ & $c_{\mathrm{H}_{2}}^{0}=p_{\mathrm{H}_{2}}^{0} / R T$ & $c_{\mathrm{H}_{2} \mathrm{O}}^{0}=p_{\mathrm{H}_{2} \mathrm{O}}^{0} / R T$ & $-i_{\text {trans }}^{\text {an }} / 2 F$ & $i_{\text {trans }}^{\text {an }} / 2 F$ & \\
\hline & Boundary & \multicolumn{2}{|c|}{ Cathode-electrolyte interface } & \multicolumn{2}{|c|}{ Anode-electrolyte interface } & Others \\
\hline \multirow{2}{*}{$\begin{array}{c}\text { Air } \\
\text { transport } \\
\text { equation }\end{array}$} & $\begin{array}{l}\text { Boundary } \\
\text { Type }\end{array}$ & $\begin{array}{c}\mathrm{O}_{2} \text { molar } \\
\text { concentration }\end{array}$ & $\begin{array}{c}\mathrm{N}_{2} \text { molar } \\
\text { concentration }\end{array}$ & $\begin{array}{c}\mathrm{O}_{2} \text { normal } \\
\text { inward molar } \\
\text { flow }\end{array}$ & $\begin{array}{c}\mathrm{N}_{2} \text { normal } \\
\text { inward molar } \\
\text { flow }\end{array}$ & Insulation \\
\hline & $\begin{array}{l}\text { Boundary } \\
\text { setting }\end{array}$ & $c_{\mathrm{O}_{2}}^{0}=p_{\mathrm{O}_{2}}^{0} / R T$ & $c_{\mathrm{N}_{2}}^{0}=p_{\mathrm{N}_{2}}^{0} / R T$ & $-i_{\text {trans }}^{\mathrm{ca}} / 4 F$ & 0 & \\
\hline
\end{tabular}


Table. 3

\begin{tabular}{|c|c|}
\hline Parameter & Value \\
\hline Fuel input mass flow rate (gr/s) [39] & 0.000094 \\
\hline Air input mass flow rate $(\mathrm{gr} / \mathrm{s})[39]$ & 0.0049 \\
\hline Input air temperature $\left({ }^{\circ} \mathrm{C}\right)[39]$ & 800 \\
\hline Input fuel temperature $\left({ }^{\circ} \mathrm{C}\right)[39]$ & 800 \\
\hline Input hydrogen mole fraction [39] & 0.8 \\
\hline Input air and fuel pressure (kpa) [39] & 101 \\
\hline Anode thickness (mm) [39] & 0.5 \\
\hline Electrolyte thickness (mm) [39] & 0.025 \\
\hline Cathode thickness (mm) [39] & 0.03 \\
\hline Tortuosity $\tau$ & 3.5 \\
\hline Porosity $\varepsilon$ & 0.3 \\
\hline Pore radii $r_{g}(\mathrm{~m})$ & $5 \times 10^{-7}$ \\
\hline Activation energies for cathode $E_{\mathrm{O}_{2}}\left(\mathrm{~J} \mathrm{~mol}^{-1}\right)$ & $130 \times 10^{3}$ \\
\hline Forward and reverse reaction symmetry factors of cathode $\alpha_{\mathrm{f}}^{\mathrm{ca}}, \beta_{\mathrm{r}}^{\mathrm{ca}}$ & $0.75,0.5$ \\
\hline Empirical constant $i_{\text {ref }}^{\mathrm{ca}}\left(\mathrm{A} \mathrm{m}^{-1}\right)$ & 860 \\
\hline Empirical constant $i_{\text {ref }}^{\text {an }}\left(\mathrm{A} \mathrm{m}^{-1}\right)$ & 2000 \\
\hline Activation energies for cathode $E_{\mathrm{H}_{2}}\left(\mathrm{~J} \mathrm{~mol}^{-1}\right)$ & $120 \times 10^{3}$ \\
\hline Forward and reverse reaction symmetry factors of anode $\alpha_{\mathrm{f}}^{\mathrm{an}}, \beta_{\mathrm{r}}^{\mathrm{an}}$ & $1,0.5$ \\
\hline Open circuit voltage $V_{o p}(\mathrm{~V})$ & 0.7 \\
\hline Contact resistance $A S R_{\text {contact }}\left(\Omega \mathrm{cm}^{2}\right)$ & 0.03 \\
\hline
\end{tabular}




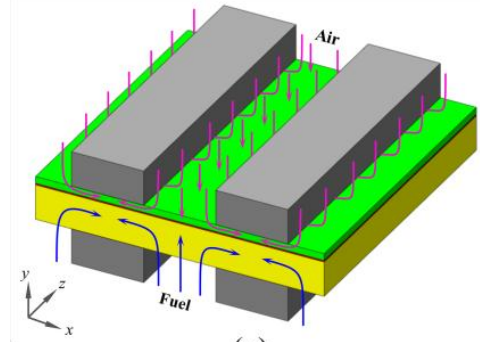

(a)

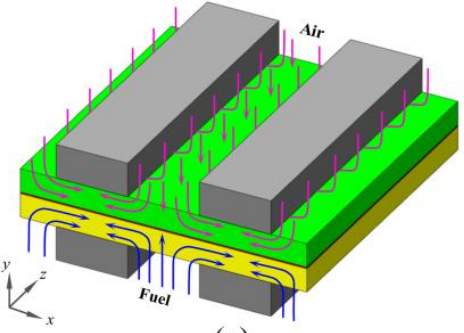

(c)

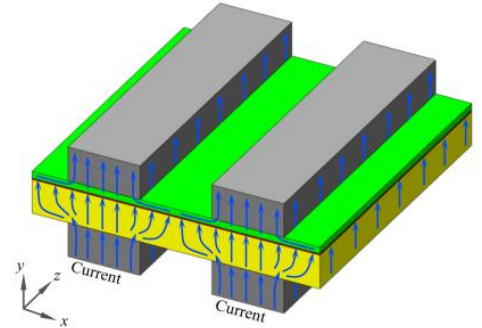

(b)

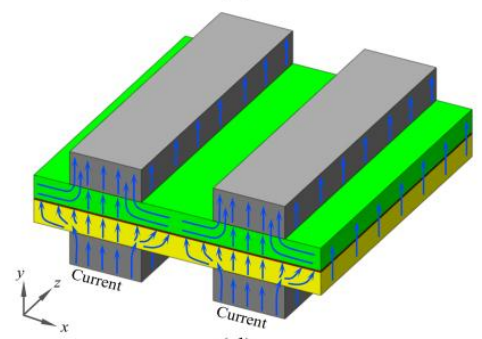

(d)

Fig. 1

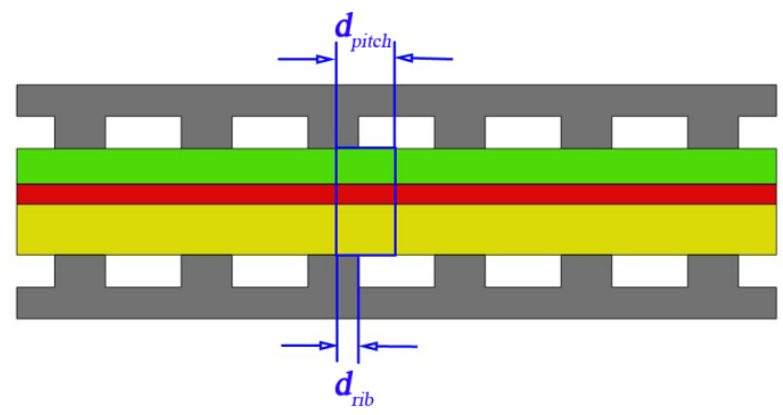

Fig. 2 


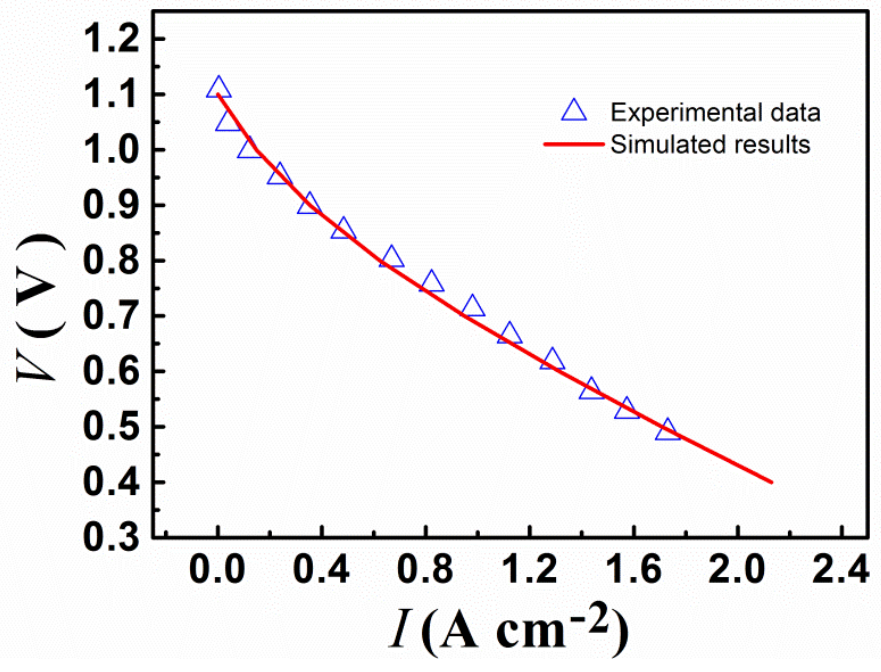

Fig. 3

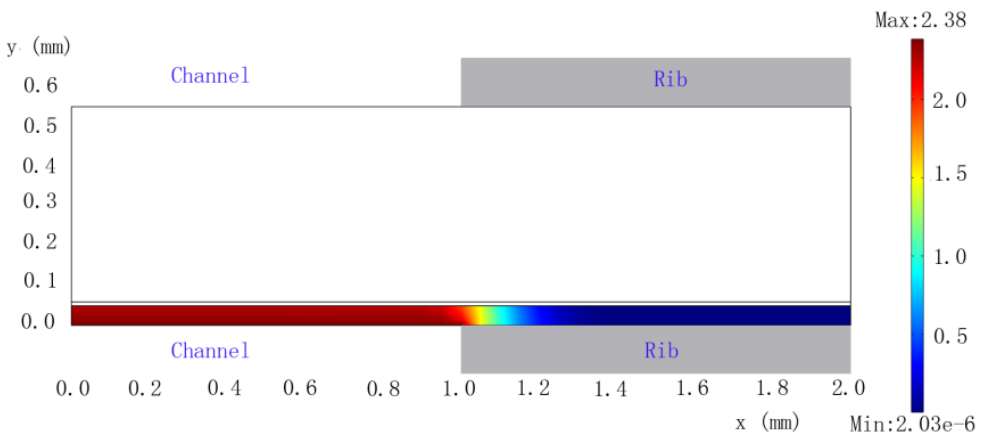

Fig. 4 (a)

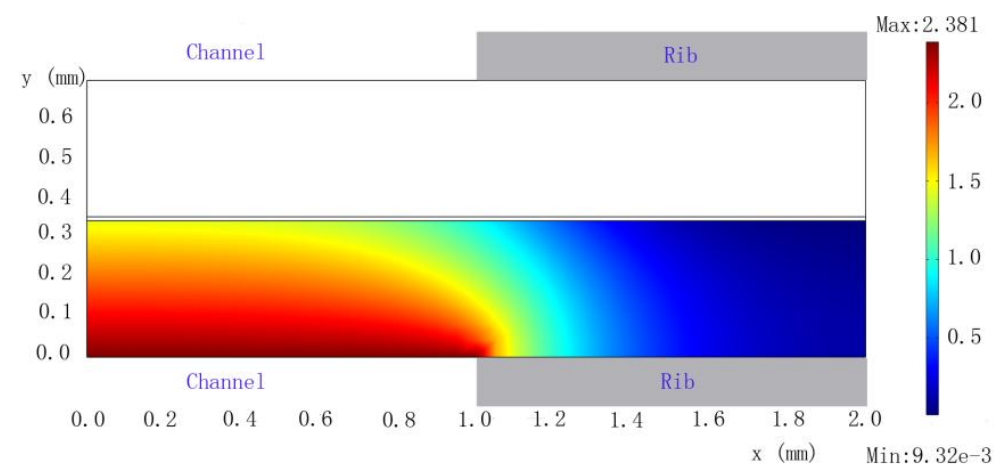

Fig. 4 (b) 


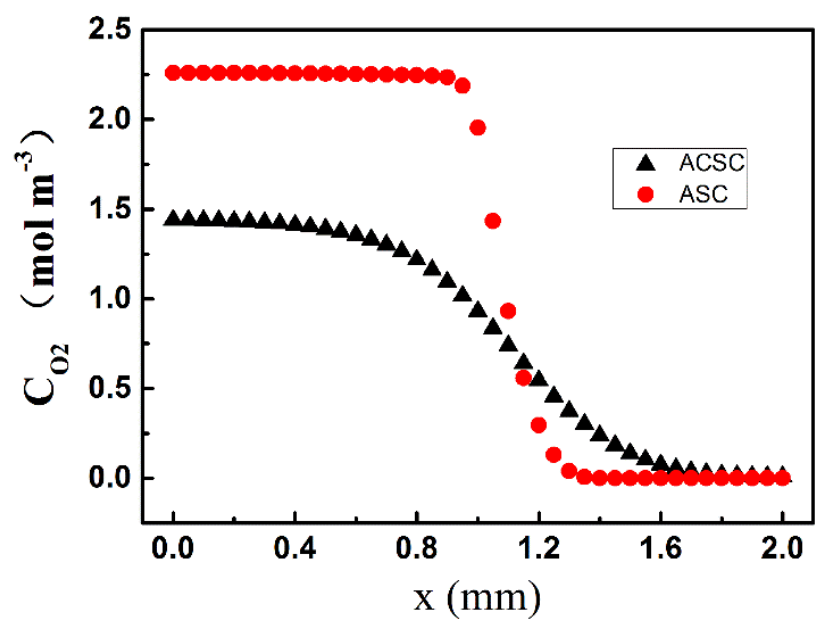

Fig. 4 (c)

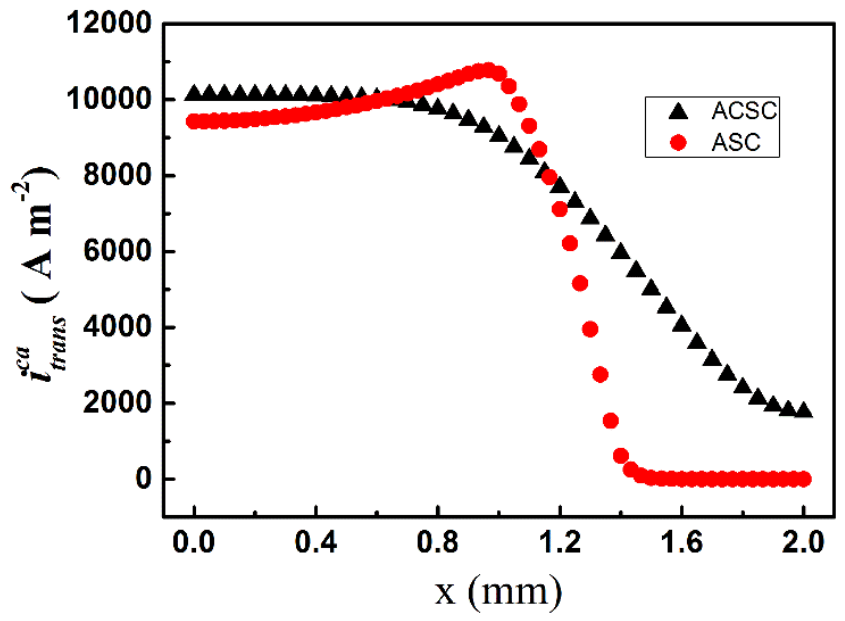

Fig. 4 (d) 


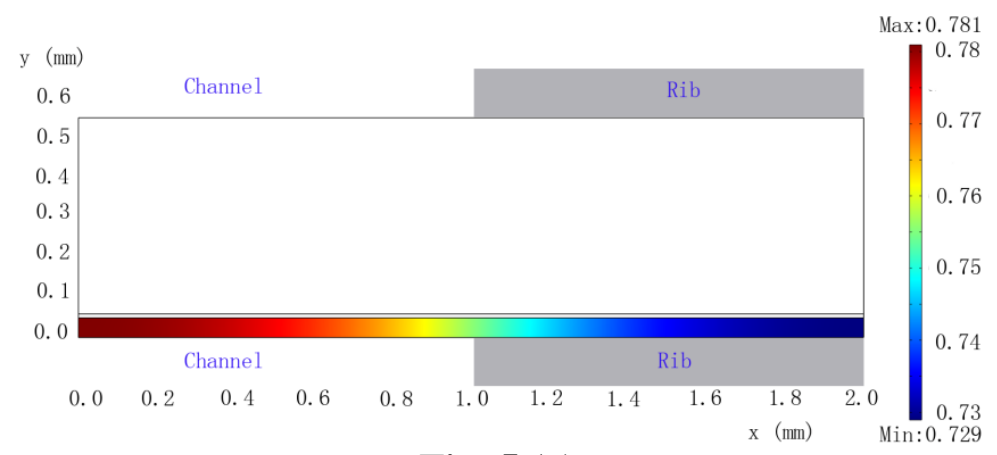

Fig. 5 (a)

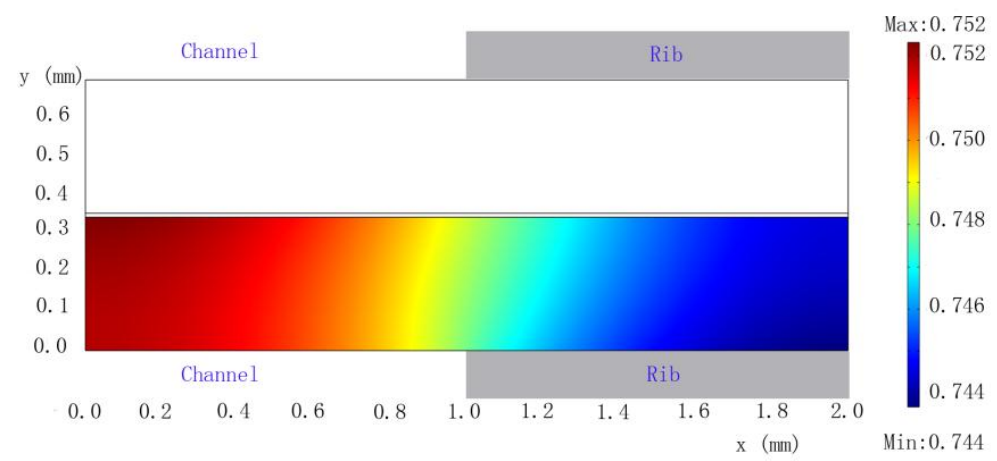

Fig. 5 (b)

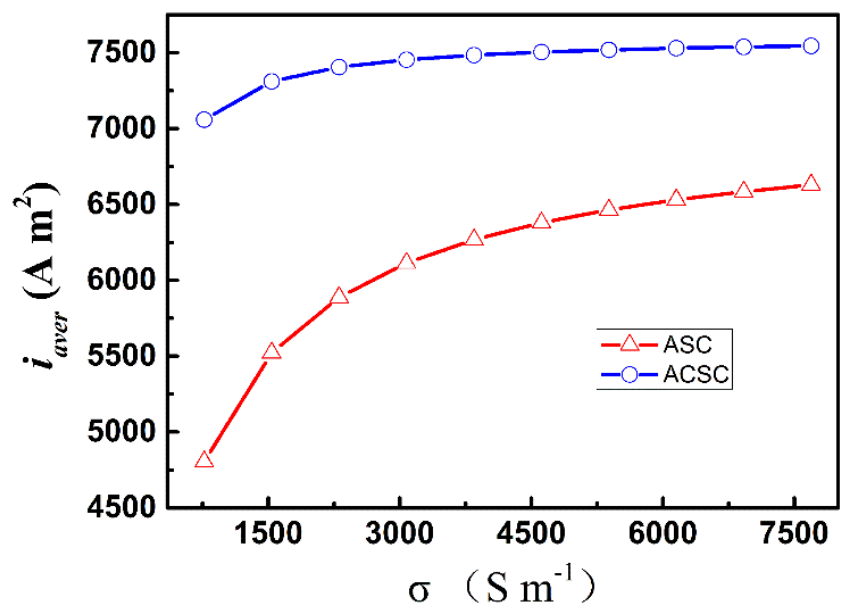

Fig. 6 


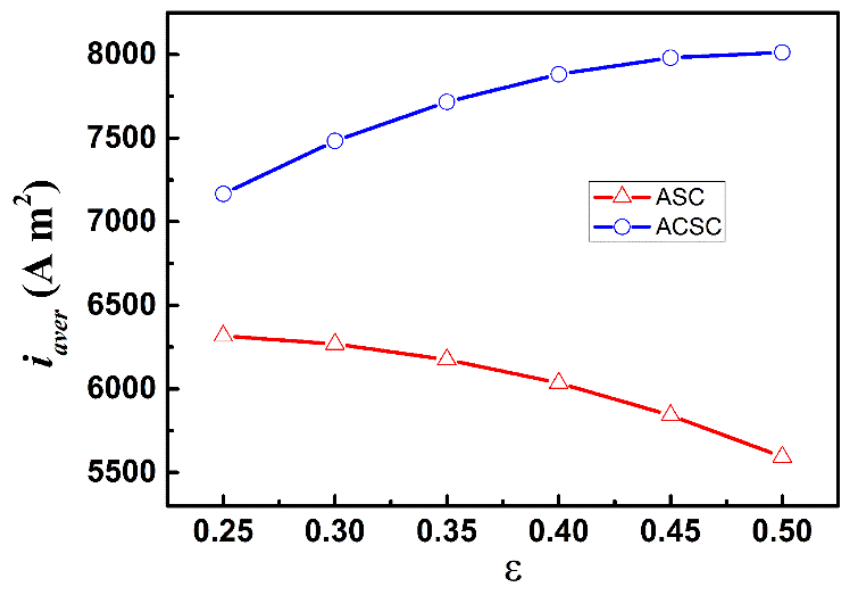

Fig. 7

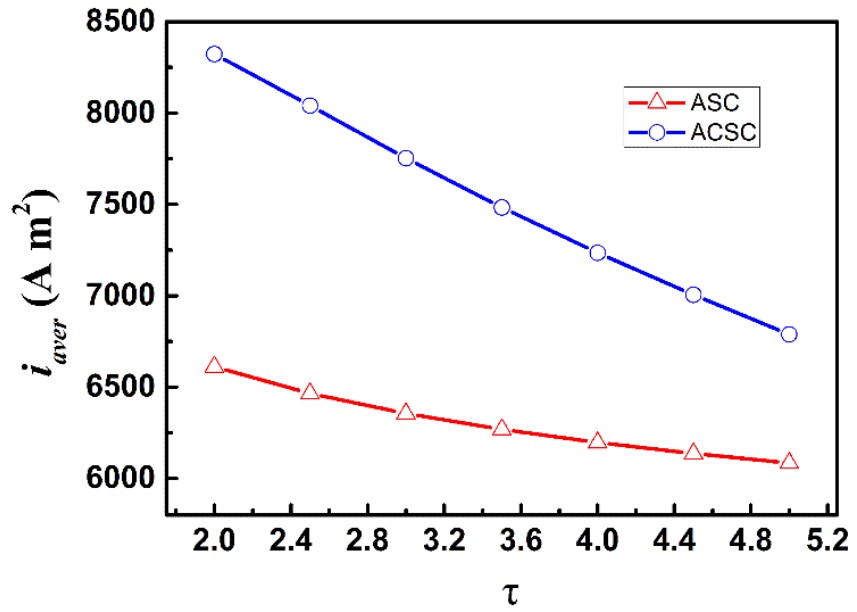

Fig. 8 


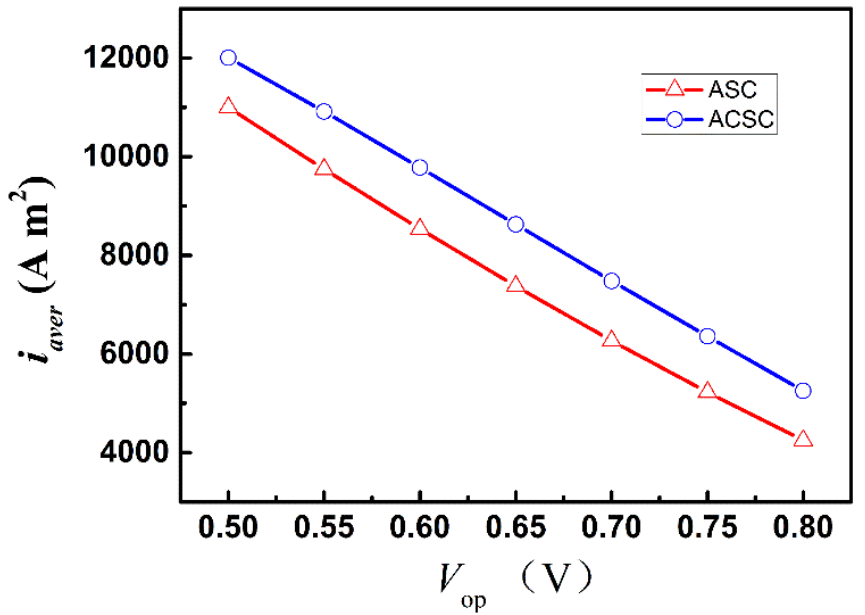

Fig. 9 